\section{Greenwich Observatory to move to Cambridge}

THE decision to move Britain's oldest observatory has finally been taken by the Science and Engineering Research Council (SERC). The Royal Greenwich Observatory (RGO) is to move from its present site at Herstmonceux Castle in Sussex to Cambridge, where it will sit alongside the university's Institute of Astronomy.

The decision has come as a relief to many of RGO's astronomers who feared that SERC might try to force through a move to the Royal Observatory at Edinburgh, the course of action recommended in an earlier report and bitterly opposed by RGO staff. Worries over the move have been heightened by the apparent unwillingness of SERC to be frank. The week before last, the matter was raised in the House of Lords and the procedures adopted by SERC for dealing with the case described as "grossly inadequate". In particular SERC failed to make public an earlier report spelling out the options for $\mathrm{RGO}$, and failed to canvass adequately astronomers' opinions.

Opinions are now divided at RGO; some, particularly those among the research-orientated staff, feel there may be new opportunities in a close association with Cambridge. For others a move to Cambridge simply means uprooting homes and family and their official reaction has been "decision received with disbelief". Opposition is certain to continue.

Herstmonceux is RGO's second home, Greenwich having been abandoned in 1948 in search of clearer skies. But now the need for even better viewing conditions means that its activities centre on the new 4.2-m William Herschel telescope being built in collaboration with Spain and the Netherlands at La Palma in the Canary Islands. By 1990, its initial instrumentation will be complete and RGO's 190 staff will probably be reduced to around 100 at the observatory and 30 at La Palma. The move to Cambridge will also take place in 1990.

For SERC, that move is dictated by its corporate plan, adopted in December 1985 , to operate its establishments in support of universities and polytechnics rather than as independent research institutes. The thinking behind that is simple enough: with present staff numbers there is time for only a little independent research at institutions, 90 per cent of the effort has to go to developing and managing research facilities for the academic community. Without powerful input from the universities, there is a risk they would lose touch with the leading edge of research. Thus, the argument runs, it makes sense for RGO to have a close association with other astronomers at a university. Some RGO researchers agree and see a better chance for spending their 10 per cent of research time profitably at Cambridge.

The risk, of course, is that an observatory closely linked to one university will cease to function as an open national institute. Before making the decision to move RGO, the SERC council apparently did consider, and reject, the alternative of building up the observatory so that it could function as a powerful independent institute. Quite how it has arrived at this decision is unclear for the cost of moving the entire institute might seem to be greater than of increasing research there, especially when disruption to the Herschel project at a critical stage in its development is taken into account.

In rolling out the welcome mat at Cambridge, Professor Martin Rees has been at pains to point out that Cambridge will not gain special rights "through propinquity". Some financial savings can be expected as libraries, computers and the like can be shared. The combined force at Cambridge should then be a match for any of the overseas astronomical competitors, like those at Arizona and Pasadena. That in turn should give Britain a foothold in the next generation of giant telescopes where international cooperation is bound to be necessary on an even bigger scale. Even now, a ten-nation plan for a $15-18 \mathrm{~m}$-telescope at La Palma is under consideration.

The loser in the move is the University of Sussex, which, although 20 miles from Herstmonceux, has made considerable use of its facilities and has 7 visiting staff from RGO. The Sussex astronomers - 4 faculty, 6 post-docs and $23 \mathrm{PhD}$ and MSc students - are now very concerned about the future. Although particularly strong in theoretical astronomy, half their work involves observation at RGO. What they will now do has yet to be decided.

One thing not yet clear is how the move have been given that the move will be selffinancing; that means that the money raised from selling off Herstmonceux Castle will pay for the move. But it is by no means clear that this is really possible; so little information has been released by SERC, and the market for castles is so hard to assess, that the possibility the move will fall through cannot be totally dismissed. to Cambridge is to be paid for. Assurances
Monoclonal antibodies Kidney rejection at bay

\section{Washington}

A MONOCLONAL antibody that reduces kidney transplant rejections last week won approval from the Food and Drug Administration (FDA), marking the first commercialized therapeutic use of the British-born technology in the United States. The drug could benefit over 5,000 transplant patients each year and pave the way for other antibody treatment schemes on the horizon. As a therapeutic tool, monoclonal antibody techniques may, however, involve limitations that have not clouded their success in diagnostics.

The drug, a product of Ortho Pharmaceutical Corporation in Raritan, New Jersey, acts by specifically neutralizing the $\mathrm{T}$ cells responsible for renal rejection. In clinical trials, it reversed approximately 94 per cent of rejections in patients receiving antibody intravenously. Conventional steroid treatment ordinarily results in a 75 per cent reversal rate. Because it is targeted to a particular leukocyte, the antibody does not suppress the entire immune system, but it can cause chills, fever and nausea.

Ortho is hoping that its treatment will eventually supplant conventional methods for combating acute rejection. So far, however, the drug cannot be used as a general maintenance immunosuppressive agent (administered over months rather than days) because it is thought that the body may mount an immune response to monoclonals derived from mouse spleen hybridomas. This problem has surfaced before, most notably in cancer treatment, the major focus of monoclonal antibody therapy. Researchers say the only way to circumvent it may be to rely on hybridomas of human cells alone.

Ortho's achievement caps a development drive initiated in 1979 , just a few years after the first description of hybridoma culture by Medical Research Council investigators Kohler and Milstein (Nature 256, 495; 1975).

Biotechnology division president Dennis Longstreet estimates a market of between $\$ 15$ and $\$ 20$ million annually in the United States for the product, which also received approval in France and Switzerland last winter and is currently awaiting word from Italy.

Monoclonal antibodies for cancer treatment are already in clinical trials, and other immunological therapies seem likely candidates for future testing. Despite potential shortcomings, there is good cause to believe that FDA's action ushers in a new era for monoclonal antibody applications.
Karen Wright 